\title{
Community-based exercise training for people with chronic respiratory and chronic cardiac disease: a mixed-methods evaluation
}

This article was published in the following Dove Press journal:

International Journal of COPD

16 November 2016

Number of times this article has been viewed

\author{
Renae J McNamara ${ }^{1,2}$ \\ Zoe J McKeough ${ }^{3}$ \\ Laura $\mathrm{R} \mathrm{Mo}^{3}$ \\ Jamie T Dallimore ${ }^{4}$ \\ Sarah M Dennis ${ }^{3}$ \\ 'Physiotherapy Department, \\ ${ }^{2}$ Respiratory and Sleep Medicine \\ Department, Prince of Wales Hospital, \\ Randwick, ${ }^{3}$ Discipline of Physiotherapy, \\ The University of Sydney, Lidcombe, \\ ${ }^{4}$ Eastern Sydney Medicare Local, \\ Rosebery, NSW, Australia
}

Background: Poor uptake and adherence are problematic for hospital-based pulmonary and heart failure rehabilitation programs, often because of access difficulties. The aims of this mixed-methods study were to determine the feasibility of a supervised exercise training program in a community gymnasium in people with chronic respiratory and chronic cardiac disease, to explore the experiences of participants and physiotherapists and to determine if a community venue improved access and adherence to rehabilitation.

Methods: Adults with chronic respiratory and/or chronic cardiac disease referred to a hospitalbased pulmonary and heart failure rehabilitation program were screened to determine their suitability to exercise in a community venue. Eligible patients were offered the opportunity to attend supervised exercise training for 8 weeks in a community gymnasium. Semi-structured interviews were conducted with participants and physiotherapists at the completion of the program.

Results: Thirty-one people with chronic respiratory and chronic cardiac disease (34\% males, mean [standard deviation] age 72 [10] years) commenced the community-based exercise training program. Twenty-two (71\%) completed the program. All participants who completed the program, and the physiotherapists delivering the program, were highly satisfied, with reports of the community venue being well-equipped, convenient, and easily accessible. Using a community gymnasium promoted a sense of normality and instilled confidence in some to continue exercising at a similar venue post rehabilitation. However, factors such as cost and lack of motivation continue to be barriers.

Conclusion: The convenience and accessibility of a community venue for rehabilitation contributed to high levels of satisfaction and a positive experience for people with chronic respiratory and chronic cardiac disease and physiotherapists.

Keywords: pulmonary rehabilitation, exercise, qualitative, COPD

\section{Background}

People with a chronic respiratory disease, such as COPD, and people with a chronic cardiac disease, such as congestive cardiac failure, frequently experience symptoms such as dyspnea and fatigue that reduce their level of daily activity ${ }^{1,2}$ and significantly impair their quality of life. ${ }^{3,4}$ Pulmonary rehabilitation, incorporating supervised exercise training as the main component, has been shown to reduce dyspnea ${ }^{5}$ and improve quality of life and functional exercise capacity, ${ }^{6,7}$ and hence it is an effective treatment option for people with chronic respiratory and chronic cardiac diseases. Despite the reported benefits, $<1 \%$ of people with moderate-to-severe COPD have attended pulmonary rehabilitation in Australia, ${ }^{8}$ and uptake in other countries is similarly suboptimal $(0.9 \%-1.4 \%) .{ }^{9-11}$ The non-attendance rate among those referred for
Correspondence: Renae J McNamara Physiotherapy Department, Prince of Wales Hospital, High Street Randwick, NSW 203I, Australia

Tel $+6 \mid 29382285$ |

Fax +6I 293822868

Email renae.mcnamara@health.nsw. gov.au 
pulmonary rehabilitation has been reported as $8 \%-50 \%$, and $10 \%-32 \%$ of patients who start do not complete a pulmonary rehabilitation program. ${ }^{12}$ The major reasons for these findings include difficulties with transport such as parking and availability of public transport, mobility, distance, and location of the program. ${ }^{12}$ According to a report conducted by Lung Foundation Australia, the majority of pulmonary rehabilitation programs in Australia are restricted to hospitals in urban and large regional centers. ${ }^{13}$ This poses a major barrier for many people living in areas outside of major hospital centers, as do long waiting periods to access a program, with half of the centers indicating that patients have to wait $>4$ weeks to start a new program after an acute exacerbation of their chronic respiratory disease. ${ }^{13}$

Community-based rehabilitation provided in a local gymnasium or community center is a potential solution to overcome barriers of access and increase the uptake and adherence of pulmonary rehabilitation. It is suitable for lowrisk patients who do not require supplementary oxygen or have health conditions that may require access to emergency medical care. ${ }^{14}$ There is evidence in the United Kingdom that community-based pulmonary rehabilitation can be delivered safely in non-hospital environments and has similar effects in improving exercise capacity and quality of life as hospitalbased pulmonary rehabilitation. ${ }^{15,16}$ However, a description of the community-based venue was not provided in one study $^{15}$ and in the other study, there was no leisure center available in the community with the ability to join on an ongoing basis, so church halls were used instead. ${ }^{16}$ A recent Australian prospective observational study demonstrated that pulmonary rehabilitation conducted in non-health care facilities in the community is feasible and safe. ${ }^{17}$ However, there is no evidence on the experiences of delivering and receiving community-based exercise training in a community gymnasium in Australia.

The aims of this mixed-methods study were to determine the feasibility of a community-based supervised exercise training program in a local community gymnasium for people with chronic respiratory and chronic cardiac disease, explore the experiences and assess the satisfaction of participants and physiotherapists involved in a community-based exercise training program, and determine if a community venue improved access and adherence to pulmonary rehabilitation.

\section{Methods}

\section{Participant recruitment and assessment}

Funding provided for this feasibility study was time-limited and allowed for a 6-month time period for patient recruitment to a new community-based exercise program provided in a local council leisure center to assist with reducing the waiting time to access a hospital-based pulmonary and heart failure rehabilitation program. All people with a chronic respiratory disease and a chronic cardiac disease referred to a tertiary hospital-based pulmonary and heart failure rehabilitation program who agreed to attend an initial face-to-face assessment prior to commencing pulmonary and heart failure rehabilitation at the hospital were assessed by an experienced physiotherapist. During the initial assessment, past and current medical history, height, and weight were recorded, and spirometry and two 6-minute walk tests (6MWT) were performed according to standardized guidelines. ${ }^{18,19}$ Patients completed a quality of life questionnaire (the St George's Respiratory Questionnaire ${ }^{20}$ for people with chronic respiratory disease and the Minnesota Living with Heart Failure Questionnaire $^{21}$ for people with chronic cardiac disease), the modified Medical Research Council dyspnea scale, ${ }^{22}$ and the Hospital Anxiety and Depression scale. ${ }^{23}$

As part of the feasibility study, patients were stratified as either "low risk" or "high risk" by the physiotherapist using the results of the initial assessment. Patients were not eligible for the community-based exercise program if they were deemed to be at high risk, which included people who required oxygen therapy for exercise training (restricted by community venue), were wheelchair dependent, had cognitive impairments, had body weight $>150 \mathrm{~kg}$ (due to maximum weight limit of exercise equipment), had poor hearing or vision, or were at risk of a medical adverse event requiring immediate medical care. The remaining patients were deemed to be at low risk and thus eligible for the community rehabilitation program. All low-risk patients were given the choice to attend either the community-based or hospital-based pulmonary and heart failure rehabilitation program. The patients attended the program venue of their choice twice a week for 8 weeks, during which adherence to the program was recorded. All patients who completed either program attended a post-program assessment, where the outcome measures assessed during the initial baseline assessment were repeated.

\section{Community venue}

The community venue was a recently refurbished local council leisure center with $>200$ free parking spaces on level ground directly outside of the center's entrance and large windows overlooking adjacent parklands. The facility had an extensive range of brand new exercise equipment in an air-conditioned setting with modern, moderate tempo 
music playing. The gymnasium was large and spacious with numerous rows of treadmills, exercise bikes, cross trainers, steppers and rowers, and multiple televisions able to be viewed from each exercise machine, similar to a commercial gymnasium and unlike a hospital gymnasium. Emergency first-aid equipment, including a defibrillator, was available in the center. The exercise sessions were conducted in the gym during the middle of the day while community members were also present. Two physiotherapists from the hospital led the sessions in the community gym with up to 10 participants. Exercise intensity was prescribed from the best 6MWT result for both walking and cycling training and by encouraging participants to exercise at a level of 3-4 on the modified BORG dyspnea scale. ${ }^{24}$ Participants were monitored by the physiotherapists with a handheld pulse oximeter (Nonin Onyx II 9550, Nonin, USA).

\section{Qualitative evaluation}

Qualitative methods were used on completion of the program to explore the experiences, access to, and level of satisfaction of the patients attending the community program and of the physiotherapists delivering the program in the community venue. Patients who attended the community venue on a minimum of four occasions were invited to participate in a semi-structured interview after their final exercise session (including those patients who did not complete the program), which lasted $\sim 15-20$ minutes. The three physiotherapists involved in delivering and supervising the communitybased exercise sessions and who were not involved as investigators on the study were also invited to take part in a semi-structured interview at the conclusion of the 6-month trial. All patients and physiotherapists were given the option of a face-to-face or telephone interview conducted by an independent research assistant. Semi-structured interviews (Supplementary materials) were chosen to allow patients and physiotherapists to express their views and experience in a purposeful but unbiased manner. ${ }^{25}$ Patients were also invited to complete a purpose-designed satisfaction survey that contained 10 statements with a five-point scale with responses ranging from "strongly agree" to "strongly disagree" (Table S1).

\section{Data analysis}

Statistical analysis for quantitative data was performed using SPSS Statistics 17.0 (SPSS Inc., Chicago, IL, USA). A paired $t$-test was used to examine the changes between baseline and post-program outcomes. A $P$-value $<0.05$ was considered to be statistically significant. Descriptive statistics were used to analyze the survey responses. The qualitative interviews were digitally recorded and professionally transcribed verbatim. The transcripts were coded by one researcher (LM) using the QSR nVIVO (v10.2.1) software. The first three transcripts were re-coded by a second researcher (SD) and compared for consistency in the coding and any discrepancies discussed with the research team. Thematic analysis was undertaken, and the coded text was organized under major and minor themes. The emerging themes were discussed among four members of the research team (RM, ZM, LM, SD) until a consensus was reached. Further reflection and coding were undertaken that produced major and minor themes. Major themes related to the experiences of the participants in relation to the community venue. Themes were considered minor if they related to benefits of pulmonary and heart failure rehabilitation more generally and were not specific to the community venue.

Ethical approval was granted by the South Eastern Sydney Local Health District Human Research Ethics Committee, and written informed consent was obtained from all participants (HREC reference number AU/6/53CA115). The guidelines for good reporting of a mixed-methods study (GRAMMS) were used. ${ }^{26}$

\section{Results}

Of 76 people with chronic respiratory or chronic cardiac disease attending an initial pulmonary and heart failure rehabilitation assessment, 67 people were low risk and eligible for the community-based venue. Thirty-two of the 67 eligible people chose to attend rehabilitation at the community venue (Figure 1), with 31 people commencing the program and $22(71 \%)$ completing the 8-week program. Participants attended a mean of 15 out of 16 sessions at the community venue. Characteristics of participants attending the community venue are presented in Table 1.

Access to pulmonary and heart failure rehabilitation improved over the 6-month community-based program trial period. The mean waiting time to commence the hospital-based program prior to the commencement of the community-based program was 59 days. At the completion of the 6-month community-based program recruitment period, the mean waiting period to access pulmonary and heart failure rehabilitation was 7 days.

There was a significant within-group improvement in 6-minute walk distance and modified Medical Research Council dyspnea scale following training in the group of participants in the community, with a trend toward a significant improvement in the total score of the St George's 


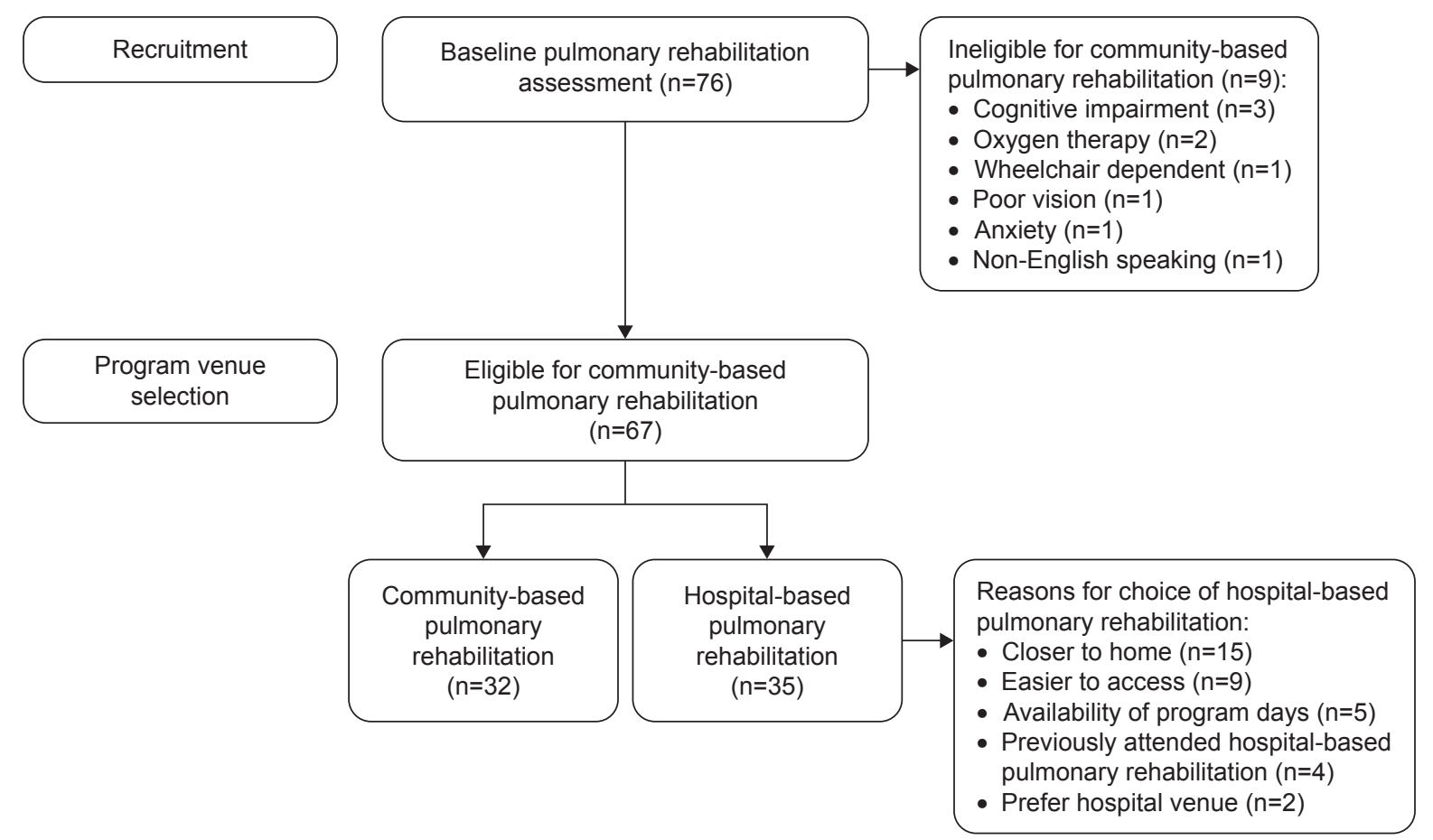

Figure I Participant flow.

respiratory Questionnaire for the chronic respiratory disease participants (Table 2).

Twenty-one participants who commenced the communitybased exercise program were able and willing to complete

Table I Participant characteristics

\begin{tabular}{|c|c|c|}
\hline Characteristic & $\begin{array}{l}\text { All } \\
\text { participants, } \\
n=32\end{array}$ & $\begin{array}{l}\text { Participants } \\
\text { interviewed, } \\
n=15\end{array}$ \\
\hline Age, years & $72(10)$ & $73(6)$ \\
\hline Gender, male:female & $|1: 2|$ & $5: 10$ \\
\hline Current smokers, $\mathrm{n}$ & 3 & 1 \\
\hline $\mathrm{BMI}, \mathrm{kg} / \mathrm{m}^{2}$ & $29(7)$ & $30(7)$ \\
\hline \multicolumn{3}{|l|}{ Primary diagnosis, $n$} \\
\hline Asthma & 5 & 2 \\
\hline Bronchiectasis & 3 & 3 \\
\hline COPD & 15 & 6 \\
\hline Congestive cardiac failure & 2 & I \\
\hline $\begin{array}{l}\text { Hypertrophic obstructive } \\
\text { cardiomyopathy }\end{array}$ & 1 & I \\
\hline Interstitial pulmonary fibrosis & 1 & - \\
\hline Lung cancer & 1 & - \\
\hline Postpartum cardiomyopathy & I & - \\
\hline Pulmonary hypertension & 3 & 2 \\
\hline \multicolumn{3}{|l|}{ Pulmonary function* } \\
\hline $\mathrm{FEV}_{1}(\mathrm{~L})$ & $\mathrm{I} .42(0.44)$ & $1.58(0.50)$ \\
\hline $\mathrm{FEV}_{1}$ (\% predicted) & $6 \mathrm{I}(20)$ & $67(22)$ \\
\hline
\end{tabular}

Notes: Data are presented as mean (SD) unless otherwise stated. ${ }_{n}=25$ for "all participants" and n=I I for "participants interviewed". "-" indicates not applicable. Abbreviations: $\mathrm{n}$, number; BMI, body mass index; $\mathrm{FEV}_{1}$, forced expiratory volume in I second; SD, standard deviation. the satisfaction survey. Of these, 19 participants had completed the 8-week program; two participants did not complete the program due to new medical conditions unrelated to their COPD and asthma that required urgent medical intervention.

Satisfaction with the community-based program was extremely high, with $100 \%$ of participants indicating that they agreed or strongly agreed with the statements "the exercise program was enjoyable", "the exercise program has improved my fitness", "the exercise program has improved my breathing when performing activities", and "I would recommend this exercise program to others with a lung or heart condition". Only one participant indicated that they disagreed with the statement "the venue of the exercise program was convenient for me (eg, transport/parking was easy)".

Of 28 participants who attended a minimum of four exercise sessions in the community venue, 24 participants were invited to partake in the semi-structured interviews. The reasons for not being invited to participate in the interview included death of participant $(n=2)$ and acute illness $(n=2)$. Of the 24 participants invited to be interviewed, 23 participants consented, with one participant declining due to disinterest. However, eight participants did not undertake the semi-structured interview due to insufficient comprehension of English $(n=3)$, new cancer diagnosis $(n=2)$, failure to complete and return the consent form $(\mathrm{n}=2)$, and being 
Table 2 Quantitative outcomes

\begin{tabular}{|c|c|c|c|c|c|}
\hline Outcome measure & $\mathbf{n}$ & Baseline & Follow-up & Change & $P$-value \\
\hline 6-minute walk distance, $\mathrm{m}$ & 22 & $408(77)$ & $440(77)$ & $32(11$ to 53$)$ & 0.005 \\
\hline St George's Respiratory Questionnaire ${ }^{\#}$ & 17 & & & & \\
\hline Total score & & $44(19)$ & $40(20)$ & $-4(-10$ to $I)$ & 0.09 \\
\hline Symptoms score & & $56(18)$ & $53(23)$ & $-3(-12$ to 5$)$ & 0.40 \\
\hline Activity score & & $59(19)$ & $52(22)$ & $-6(-12$ to -1$)$ & 0.03 \\
\hline Impact score & & $32(23)$ & $26(19)$ & $-6(-13$ to 1$)$ & 0.08 \\
\hline Minnesota Living with Heart Failure Questionnaire & 4 & & & & \\
\hline Total score & & $54(25)$ & $4 I(22)$ & $-12(-33$ to 8$)$ & 0.16 \\
\hline mMRC dyspnea scale ${ }^{\#}$ & 22 & $3.2(1.1)$ & $2.7(1.1)$ & $-0.5(-0.9$ to -0.1$)$ & 0.008 \\
\hline HAD scale & 21 & & & & \\
\hline Anxiety score & & $6.5(4.6)$ & $6.1(5.0)$ & $-0.3(-1.8$ to 1.2$)$ & 0.65 \\
\hline Depression score & & $5.8(4.4)$ & $4.8(3.5)$ & $-1.0(-2.3$ to 0.3$)$ & 0.13 \\
\hline
\end{tabular}

Notes: Data are presented as mean (SD) or mean $(95 \% \mathrm{Cl})$, unless otherwise stated. "Lower score equates to better outcome. $\mathrm{n}$ denotes the sample size.

Abbreviations: mMRC, modified Medical Research Council; HAD, Hospital Anxiety and Depression; SD, standard deviation; Cl, confidence interval.

uncontactable $(\mathrm{n}=1)$. The 15 remaining participants took part in the semi-structured interviews. Characteristics of participants involved in the qualitative component of the study are presented in Table 1. Two of these participants had previously attended the hospital-based pulmonary rehabilitation program. There were three physiotherapists involved with the delivery of the community-based program, and all participated in the semi-structured interviews. These physiotherapists were all females with a mean (standard deviation) 9 (4) years of physiotherapy clinical experience.

Four major themes and three minor themes emerged from the semi-structured interviews with participants and physiotherapists. Quotes from interviewees for the major themes are reported in Table 3 .

\section{Major theme I - community venue and environment facilitated a positive rehabilitation experience}

All interviewees were positive about the community venue, with reports that the environment promoted a sense of "normality" within the rehabilitation experience for both the participants and the physiotherapists, with the pleasant outlook over parklands and multiple television screens contributing to a more relaxed environment compared to the gym at the hospital. With a wider range of new exercise machines available than the hospital gym, many participants liked the opportunity to use a variety of machines according to their personal preference and physical capabilities. This provided a source of motivation and engagement with the exercise training program. The wide range of exercise equipment also allowed the physiotherapists to be more flexible with their intervention and individualize each participant's exercise program.

\section{Major theme 2 - convenience of accessing the community venue}

Many participants reported that even though they were not familiar with the community venue, the ease of access with close proximity of free parking to the community gym was appealing and an important factor in determining the decision to choose the community-based program over the hospitalbased program. Most participants said that the hospital was very difficult and expensive for parking. The physiotherapists agreed that this factor meant that patients were not as physically tired getting to the gym.

\section{Major theme 3 - normalizing and transference of behaviors}

The community gym allowed participants to perceive exercise as a normal, healthy behavior undertaken by people of all ages in the community rather than a treatment supervised and enforced by the physiotherapists at the hospital. The venue not only promoted more positive attitudes toward exercise but also a sense of inclusion within the community. The community-based exercise training program also exposed participants to a community gym setting and fostered their confidence to explore how they might continue exercising in a similar venue in the future instead of the hospital environment.

\section{Major theme 4 - barriers to post- program exercise}

Although the participants valued the program, many lacked the motivation to continue exercising at the community gym or another community setting following completion of the program. They reported difficulty in initiating and maintaining an exercise routine independently particularly 
Table 3 Major themes and quotes from interviews

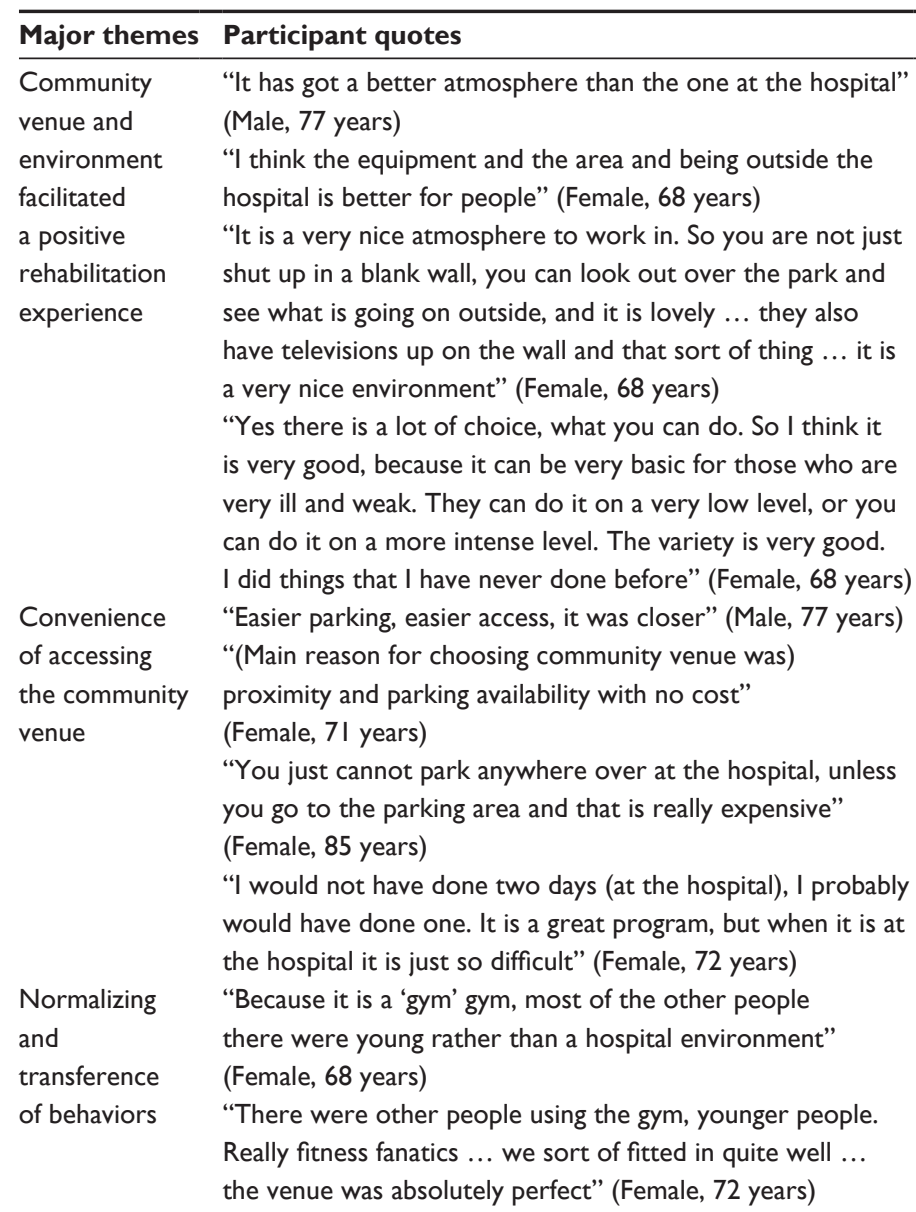

Barriers to post-program exercise

\section{Physiotherapist quotes}

"It is good to get out of the hospital setting and see the real-world setting and seeing these people exercising in the community in that way" (Physiotherapist I)

"They were probably doing more exercise than they might do at one of the hospital venues that is setup for older people ... rather than only having a few options for them ... flexibility to be able to vary people's programs, try different things with them" (Physiotherapist I)

"The fact they could just park outside and have a short walk in, they were more confident, they were not getting anxious about the parking, because some of them do get quite anxious, just the idea of I have got to park, then I have got to walk, but they knew what was going to happen at the community venue" (Physiotherapist 2) "They were less fatigued when they got there" (Physiotherapist 3) "The whole concept of access to the facility was a thing that made them attend more" (Physiotherapist 2)

"They got to see some other people their own age who were just coming to use the gym independently, so they could see other older people exercising" (Physiotherapist 3)

"It was not as institutionalized. It made the patients feel more that they were training as opposed to doing some treatment ... it makes them feel like they are less sick" (Physiotherapist 2)

"What I really enjoyed about it ... it is real life. In our society people go to the gym. So it is a sort of fostering that within them and giving them the opportunity to go outside a hospital setting into a community setting ... so they are not so institutionalized by coming back in and doing their program at the hospital" (Physiotherapist I) "They were more confident to actually be in a gym environment because they have come to a community gym. The fact that we had that little interaction sort of helped other people see, maybe I can come here with my family ... one patient is a little bit more confident now so he is looking to get his son to go to another gym so they can go together and he feels confident enough now to be able to do that, whereas before I do not know whether he would have been as confident going to the hospital gym .... it is a clinical setting" (Physiotherapist 2)

"They are not able to get motivated to go to the gym and do their own program, even though they know it very well ... they are able to set up their equipment, get on and off the equipment by themselves, use it correctly. It was just that motivation of getting to the gym" (Physiotherapist 2)

"(Main barriers to joining the gym) cost and the commitment ... they are not able to commit to the amount of sessions that they deemed to be getting value for money and also the motivation to come to the gym" (Physiotherapist 2)

"The main thing is cost ... they have other things that they might prioritize and they might think that joining a gym is a luxury compared to say health care costs ... so cost I think is probably the main barrier for a lot of the people that go to the pulmonary rehab program because the majority of them are elderly or on a pension" (Physiotherapist I) 
lacking commitment to attend ongoing exercise classes. Furthermore, the gym environment did not appeal to all participants for ongoing exercise. Another major barrier was the cost of gym membership being too expensive for participants who were either retired or on a pension and not seen as value for money.

Minor themes were considered as findings not specific to the location of the pulmonary rehabilitation program.
Quotes from interviewees for the minor themes are reported in Table 4.

\section{Minor theme I - perceived fitness benefits}

By having the opportunity to attend and experience the benefits of exercise, participants were able to see the value of the program. Many commented on their improved level of fitness

Table 4 Minor themes and quotes from interviews

\begin{tabular}{|c|c|c|}
\hline Minor themes & Participant quotes & Physiotherapist quotes \\
\hline $\begin{array}{l}\text { Perceived fitness } \\
\text { benefits }\end{array}$ & $\begin{array}{l}\text { "Mainly the walking machine, because I was having } \\
\text { difficulty walking up hills ... and that has improved my } \\
\text { fitness level quite considerably. So I was very pleased } \\
\text { from that point of view ... I can lift a lot heavier things } \\
\text { now ... it has improved my fitness, my lifting capability, } \\
\text { my walking capability" (Female, } 68 \text { years) } \\
\text { "The best part was getting fit so that I can walk up } \\
\text { stairs without being breathless" (Female, } 72 \text { years) } \\
\text { "There was tangible improvement ... yeah, I thought } \\
\text { the actual rate of progress was visible and it gave me a } \\
\text { lot of satisfaction" (Female, } 77 \text { years) } \\
\text { "Well I think it was showing that you can do a little bit } \\
\text { more than you thought you could, you know. Like I do } \\
\text { more now than I would have ever done before. I would } \\
\text { not have done any of those sorts of things before other } \\
\text { than walking" (Female, } 72 \text { years) }\end{array}$ & \\
\hline $\begin{array}{l}\text { Interaction facilitated } \\
\text { adherence to the } \\
\text { exercise training } \\
\text { program }\end{array}$ & $\begin{array}{l}\text { "It is very difficult to do it by yourself at home ... they } \\
\text { push you more, you just do a bit extra, a bit extra, you } \\
\text { know" (Male, } 68 \text { years) } \\
\text { "Even though it is a sort of work, it is still social and } \\
\text { you are still mixing with other people, and they are } \\
\text { people that are like you" (Female, } 72 \text { years) } \\
\text { "It gave you encouragement, that we were all trying } \\
\text { our best to achieve something and, you know, it } \\
\text { was sort of nice to have people to talk to, and after } \\
\text { eight weeks, I6 sessions, you get to know people } \\
\text { and encourage them and they encourage you" } \\
\text { (Female, } 68 \text { years) } \\
\text { "I found the interaction with people who had severe } \\
\text { illnesses and were very much incapacitated, that it } \\
\text { was very good for me to see how far I had come. The } \\
\text { group interaction was very warm and very supportive" } \\
\text { (Female, } 77 \text { years) }\end{array}$ & \\
\hline $\begin{array}{l}\text { Physiotherapists } \\
\text { importance and role }\end{array}$ & $\begin{array}{l}\text { "You had the people to show you what to do and to } \\
\text { encourage you to get started. So that has given me } \\
\text { the opportunity to think well now I can do that myself } \\
\text { because I know what to do" (Female, } 68 \text { years) } \\
\text { "If I have the physios with me I am confident, but on } \\
\text { my own I am not so confident. I actually enjoyed the } \\
\text { exercises, but I think I enjoyed the exercises because } \\
\text { I knew I was being monitored. I do not know if I could } \\
\text { go and do it on my own because I would be a bit } \\
\text { anxious" (Female, } 68 \text { years) } \\
\text { "Yeah, I was in a pretty bad way and I needed to } \\
\text { improve, but I did not feel I could go to a commercial } \\
\text { gym, I needed the physios there to monitor me and } \\
\text { support me" (Female, } 77 \text { years) }\end{array}$ & $\begin{array}{l}\text { "We do not want them to be so dependent on us once } \\
\text { they finish the program. Hopefully we have taught them } \\
\text { the skills to continue exercising on their own or joining } \\
\text { a group outside of the hospital setting ... the main } \\
\text { thing is empowering the person who has completed to } \\
\text { continue on by themselves" (Physiotherapist I) } \\
\text { "With a lot of these people right at the end of } \\
\text { the program ... it was more just checking them at } \\
\text { the start, how are you going, upping them as they } \\
\text { needed to and some people would just be increasing } \\
\text { themselves" (Physiotherapist 2) } \\
\text { "We were able to encourage them to be really } \\
\text { independent, so hopefully that will translate to them } \\
\text { being able to do that themselves" (Physiotherapist 3) }\end{array}$ \\
\hline
\end{tabular}


and physical function. These visible improvements facilitated their level of self-efficacy and confidence in their ability.

\section{Minor theme 2 - interaction facilitated adherence to the exercise training program}

Social interaction played an important role in motivating participants to attend the exercise training program. Many participants recognized that it was difficult to exercise independently and that they required the mutual encouragement of other participants and the physiotherapists. One participant highlighted that exercising with others with a similar condition allowed them to see their own progress.

\section{Minor theme 3 - physiotherapists' importance and role}

There was an interesting contrast between attitudes of the participants and the physiotherapists with regard to their role in the program. The physiotherapists believed that their role was to empower, educate, and promote transferable skills for patients to self-manage and continue exercising post trial. Some of the participants shared this attitude, as they believed that the physiotherapists had educated them to exercise independently and they had developed self-efficacy. However, other participants still required the support of the physiotherapist to motivate them and ensure their safety. At the completion of the program, they were not confident to continue exercising without the supervision from the physiotherapists.

\section{Discussion}

Supervised exercise training in a community gymnasium for people with chronic respiratory disease and chronic cardiac disease was found to be feasible, safe, and effective, with high participant and physiotherapist satisfaction. Exercise capacity and dyspnea improved significantly following the 8 -week program. The participants valued the physical environment and convenience of access and felt that exercising in a community gym normalized the rehabilitation experience. Adherence to the community-based program was influenced by the participants' perceived benefits from exercise, the social aspect of the program, and support from physiotherapists. Despite the overall positive experience, barriers, such as motivation and cost, prevented participants from believing that they would continue to exercise at the community gym after the completion of the exercise training program.
Community-based exercise training was shown to be effective in significantly improving functional exercise capacity. The improvement in 6-minute walk distance of $32 \mathrm{~m}$ surpassed the minimal clinically important difference reported in COPD. ${ }^{27}$ The changes in quality of life (measured by the St George's Respiratory Questionnaire and the Minnesota Living with Heart Failure Questionnaire) also surpassed the minimal clinically important differences reported for both of these questionnaires ${ }^{28,29}$ despite not reaching statistical significance. These results concur with previous studies from the United Kingdom and Australia, which have demonstrated improvements in functional and endurance walking capacity and quality of life following community-based pulmonary rehabilitation. ${ }^{15-17}$ This current study provides further evidence to support the delivery of community-based rehabilitation in the Australian health care context.

Physical barriers can influence a patients' adherence and completion of a pulmonary rehabilitation program. Examples of physical barriers include long waiting periods; lack of, or difficulty accessing, suitable transport; and parking difficulties. ${ }^{12,30,31}$ This trial of a community-based exercise training program aimed to overcome these barriers by offering patients referred to pulmonary and heart failure rehabilitation the ability to access rehabilitation soon after referral and the option to exercise at an alternative venue to the hospital. The availability of free parking in close proximity and with level entry to the community gym made it easier to access, which allowed patients to experience the benefits of an effective intervention for the management of their chronic respiratory or chronic cardiac disease. These factors contributed to the high completion rate.

By normalizing the rehabilitation experience for patients, the community gym setting shifts away from the diseasebased model enforced in rehabilitation programs run in the hospital setting. The opportunity to exercise in a relaxed environment around a healthy population facilitated not only a sense of inclusion in the community but also self-efficacy and confidence to exercise independently. Disappointingly, the study found that the community-based exercise training program was unable to facilitate the patients to continue to exercise at the community gym independently. One of the barriers to continued exercise identified by participants was the lack of motivation. Health coaching has the potential to overcome this by encouraging self-efficacy and behavior change that can be seen in its success in people with diabetes. ${ }^{32}$ Integrating motivational interviews has also been found to be feasible in the self-management of COPD. ${ }^{33}$ It has the 
potential to increase patient engagement but its relevance in promoting exercise needs to be further investigated..$^{33}$ These strategies could be used in the future to complement a community-based rehabilitation program. Another barrier to continued exercise identified by participants was the need for supervision of a physiotherapist in the community venue. To overcome this in Australia, exercise programs such as Lungs in Action $^{34}$ and Heart Moves ${ }^{35}$ that are supervised, but not as closely monitored or individualized, would be viable options for these patients.

Safety considerations are important when implementing a community-based pulmonary and heart failure exercise training program to prevent serious adverse events. The community gym used in this trial was well-equipped with first-aid equipment including a defibrillator, which may be unlike some community-based venues such as community halls that may not have such emergency equipment available. Furthermore, the two physiotherapists and the gym staff were all adequately trained in first-aid and basic life support. A stringent screening process was implemented to ensure participants were deemed safe to exercise outside of the hospital environment, and this resulted in participants who had predominantly mild-to-moderate disease attending the community venue.

Although participants did not mention any negative aspects about the venue in the interview, the physiotherapists highlighted some logistical difficulties such as the lack of rest areas for the participants and the physical location of bathroom facilities in relation to the gym floor. This demonstrates that when compared to the hospital venue, the inconveniences of the community venue did not affect the patients' positive experience of the community-based exercise training program.

The main limitation of this study was the lack of a randomized controlled trial design. Since the patients had the choice between the community- and hospital-based programs, some participants may already have had a more positive outlook to the community-based program and hence introduced bias to the overall experience. A structured delivery of education sessions did not form part of the community-based exercise training program; thus, the comprehensive nature of pulmonary and heart failure rehabilitation delivered in a community setting was not evaluated. To overcome these limitations, a randomized controlled trial that includes a multidisciplinary approach should be conducted in the future. A health economic evaluation to determine the cost-effectiveness of shifting pulmonary and heart failure rehabilitation into the community is also warranted.

\section{Conclusion}

Providing exercise training in a community-based setting improved access to pulmonary and heart failure rehabilitation by people with chronic respiratory disease and chronic cardiac disease. Interviews with patients and physiotherapists found high levels of satisfaction with exercise training in a community gym due to the convenience and accessibility of the venue. The setting normalized the rehabilitation experience for patients and provided a sense of inclusion with the local community, which for some patients facilitated the confidence to continue exercising at a similar venue post trial. However, barriers including cost, lack of motivation, and supervision were raised by patients as factors that could prevent them from continuing to exercise at the community gym.

\section{Acknowledgments}

The authors would like to thank Sameera Ansari for interviewing the participants for the qualitative component of the study. The community-based rehabilitation program and evaluation was funded by Eastern Sydney Medicare Local. The funding body had no role in the design of the study or collection, analysis, and interpretation of the data.

\section{Disclosure}

The authors report no conflicts of interest in this work.

\section{References}

1. Oka RK, Stotts NA, Dae MW, Haskell WL, Gortner SR. Daily physical activity levels in congestive heart failure. Am J Cardiol. 1993;71(11): 921-925

2. Reardon JZ, Lareau SC, ZuWallack R. Functional status and quality of life in chronic obstructive pulmonary disease. Am J Med. 2006; 119(10 suppl 1):32-37.

3. van Jaarsveld CH, Sanderman R, Miedema I, et al. Changes in healthrelated quality of life in older patients with acute myocardial infarction or congestive heart failure: a prospective study. J Am Geriatr Soc. 2001; 49(8):1052-1058.

4. Jones PW, Brusselle G, Dal Negro RW, et al. Health-related quality of life in patients by COPD severity within primary care in Europe. Respir Med. 2011;105(1):57-66.

5. Reardon J, Awad E, Normandin E, Vale F, Clark B, ZuWallack RL. The effect of comprehensive outpatient pulmonary rehabilitation on dyspnea. Chest. 1994;105(4):1046-1052.

6. Evans RA, Singh SJ, Collier R, Loke I, Steiner MC, Morgan MD. Generic, symptom based, exercise rehabilitation; integrating patients with COPD and heart failure. Respir Med. 2010;104(10):1472-1481.

7. McCarthy B, Casey D, Devane D, Murphy K, Murphy E, Lacasse Y. Pulmonary rehabilitation for chronic obstructive pulmonary disease. Cochrane Database Syst Rev. 2015;2:CD003793.

8. Lung Foundation Australia (LFA). Case Statement: Chronic Obstructive Pulmonary Disease (COPD). 2001. Available from: http:// lungfoundation.com.au/wp-content/uploads/2014/03/COPD-CaseStatement.pdf. Accessed March 1, 2016.

9. Yohannes AM, Connolly MJ. Pulmonary rehabilitation programmes in the UK: a national representative survey. Clin Rehabil. 2004;18(4):444-449. 
10. Brooks D, Sottana R, Bell B, et al. Characterization of pulmonary rehabilitation programs in Canada in 2005. Can Respir J. 2007;14(2): 87-92.

11. Levack WM, Weatherall M, Reeve JC, Mans C, Mauro A. Uptake of pulmonary rehabilitation in New Zealand by people with chronic obstructive pulmonary disease in 2009. N Z Med J. 2012;125(1348): 23-33.

12. Keating A, Lee A, Holland AE. What prevents people with chronic obstructive pulmonary disease from attending pulmonary rehabilitation? A systematic review. Chron Respir Dis. 2011;8(2):89-99.

13. Lung Foundation Australia (LFA). Submission to Federal Health Budget: Improving Access to Pulmonary Rehabilitation through MBS Rebate. 2015. Available from: http://lungfoundation.com.au/wpcontent/uploads/2015/02/Pre-Budget-Submision-Improving-Accessto-Pulmonary-Rehabiliatation-through-MBS-Rebate.pdf. Accessed January 18, 2016.

14. Alison J, [webpage on the Internet]. The Pulmonary Rehabilitation Toolkit. The Australian Lung Foundation; 2009. Available from: www. pulmonaryrehab.com.au. Accessed January 18, 2016.

15. Man WD, Polkey MI, Donaldson N, Gray BJ, Moxham J. Community pulmonary rehabilitation after hospitalisation for acute exacerbations of chronic obstructive pulmonary disease: randomised controlled study. BMJ. 2004;329(7476):1209.

16. Waterhouse JC, Walters SJ, Oluboyede Y, et al. A randomised $2 \times 2$ trial of community versus hospital pulmonary rehabilitation followed by telephone or conventional follow-up. Health Technol Assess. 2010; 14(6):i-v,vii-xi,1-140.

17. Cecins N, Landers H, Jenkins S. Community-based pulmonary rehabilitation in a non-healthcare facility is feasible and effective. Chron Respir Dis. 2016. Epub 2016 Jun 17.

18. American Thoracic Society (ATS). Standardization of spirometry, 1994 update. Am J Respir Crit Care. 1995;152(3):1107-1136.

19. Holland AE, Spruit MA, Troosters T, et al. An official European Respiratory Society/American Thoracic Society technical standard: field walking tests in chronic respiratory disease. Eur Respir J. 2014;44(6): 1428-1446.

20. Jones PW, Quirk FH, Baveystock CM. The St George's respiratory questionnaire. Respir Med. 1991;85(suppl):25-31.

21. Rector TS, Kubo SH, Cohn JN. Patients' self-assessment of their congestive heart failure. Part 2: content, reliability and validity of a new measure, the Minnesota living with heart failure questionnaire. Heart Fail. 1987;3:198-209.
22. Celli BR, Cote CG, Marin JM, et al. The body-mass index, airflow obstruction, dyspnea, and exercise capacity index in chronic obstructive pulmonary disease. N Engl J Med. 2004;350(10):1005-1012.

23. Zigmond AS, Snaith RP. The hospital anxiety and depression scale. Acta Psychiatr Scand. 1983;67(6):361-370.

24. Borg GA. Psychophysical bases of perceived exertion. Med Sci Sports Exerc. 1982;14(5):377-381.

25. Cohen D, Crabtree B, [webpage on the Internet]. Qualitative Research Guidelines Project. 2006. Available from: http://www.qualres.org/ HomeSemi-3629.html. Accessed January 18, 2016.

26. O'Cathain A, Murphy E, Nicholl J. The quality of mixed methods studies in health services research. J Health Serv Res Policy. 2008; 13(20):92-98.

27. Holland AE, Hill CJ, Rasekaba T, Lee A, Naughton MT, McDonald CF. Updating the minimal important difference for six-minute walk distance in patients with chronic obstructive pulmonary disease. Arch Phys Med Rehabil. 2010;91(2):221-225.

28. Jones PW. St. George's respiratory questionnaire: MCID. COPD. 2005; 2(1):75-79.

29. McAlister F, Ezekowitz J, Wiebe N, et al. Cardiac Resynchronization Therapy for Congestive Heart Failure. Evidence Report/Technology Assessment No. 106. 2004. Available from: http://archive.ahrq. gov/downloads/pub/evidence/pdf/resynchf/resynchf.pdf. Accessed January 18, 2016.

30. Fischer MJ, Scharloo M, Abbink JJ, et al. Participation and drop-out in pulmonary rehabilitation: a qualitative analysis of the patient's perspective. Clin Rehabil. 2007;21(3):212-221.

31. Guo SE, Bruce A. Improving understanding of and adherence to pulmonary rehabilitation in patients with COPD: a qualitative inquiry of patient and health professional perspectives. PLoS One. 2014;9(10): e110835.

32. Di Loreto C, Fanelli C, Lucidi P, et al. Validation of a counseling strategy to promote the adoption and the maintenance of physical activity by type 2 diabetic subjects. Diabetes Care. 2003;26(2):404-408.

33. Benzo R, Vickers K, Ernst D, et al. Development and feasibility of a COPD self-management intervention delivered with motivational interviewing strategies. J Cardiopulm Rehabil. 2013;33(2):113-123.

34. Lung Foundation Australia. Lungs in Action. Available from: http:// lungsinaction.com.au. Accessed January 18, 2016.

35. Heart Foundation. Heartmoves. Available from http://www.heartmoves. org.au. Accessed January 18, 2016. 


\section{Supplementary materials \\ Semi-structured interview questions (participants)}

1. You chose to attend the exercise program at the Des Renford Leisure Centre (rather than at the Prince of Wales Hospital). What were your reasons for choosing this option?

Probes: geographic location, type of venue, transport availability, parking, familiarity with venue

2. Did attending the program at this venue meet your initial reasons for choosing this venue? That is, how pleased were you with your choice?

3. Have you ever attended pulmonary rehabilitation before? If so, where, and how did your previous experience influence your choice this time?

4. Thinking about your experience at this exercise program, what was the best part of the rehabilitation program/what were the most useful aspects/what did you most enjoy and why?

Probes: variety of exercises, different exercise machines, the quality of the equipment, gym environment, eg, music/televisions/scenery, the physiotherapists leading the program, exercising in a group with other participants, social side, support from physiotherapists/other participants, advice, improved fitness, location, transport options/parking

5. What part of the rehabilitation program did you least enjoy and why?

Probes: travel too difficult, poor access, did not like exercise training or equipment or gym environment, other participants, assessment/testing appointments

6. Was there a financial cost or inconvenience for you to attend a rehabilitation session? Was this acceptable for you?

Probes: parking cost, petrol cost, bus ticket, travel time, time off paid work/volunteer work, time away from caring duties, etc.

7. Overall, how satisfied were you with the rehabilitation program?

8. Would you recommend this program to others and why?

9. If the rehabilitation program had only been at Prince of Wales Hospital would you have attended? Why or why not?

10. Do you intend to continue exercising now the program has finished? Why or why not?
Probes: planning to exercise at home or here at this gym or at another site or attend supervised maintenance exercise sessions/walking group, with friends

11. Is there anything else that you would like to add?

Thank you very much for your time in answering these questions.

\section{Semi-structured interview questions (physiotherapists)}

1. Did you receive any positive feedback from the patients about having the choice of two venues for the rehabilitation program?

2. Did you receive any negative feedback from the patients about having a choice of two venues for the rehabilitation program?

3. Did you receive any positive feedback from the patients about the community venue?

4. Did you receive any negative feedback from the patients about the community venue?

5. What do you perceive were the major benefits to the patients who attended the community venue?

6. What do you perceive were the drawbacks to the patients who attended the community venue?

7. What were some of the positive aspects of working in the community venue?

Probes: different exercise machines, the quality of the equipment, gym environment, eg, music/televisions/ scenery, location, transport options/parking, away from hospital environment, working autonomously

8. What were some of the negative aspects of working in the community venue?

Probes: travel time, did not like exercise equipment or gym environment, noise, distractions, open to public, no medical back-up/support

9. What could be changed in the program or venue to improve the experience for both yourself and the patients?

10. Overall, how satisfied were you with the community venue? Would you like to continue running rehabilitation out of this venue?

11. Were you aware of any patients who joined the community gym at the completion of their program? What factors do you believe facilitated them to join?

Probes: knowing physiotherapist would be in gym, felt confident and safe in environment, location, transport/ parking, facilities 
12. What do you believe were the main barriers to patients not joining the gym at the completion of their program? Probes: cost, no medical support, intimidation, location, transport/parking
13. Is there anything else that you would like to add?

Thank you very much for your time in answering these questions.

Table SI Satisfaction survey

\begin{tabular}{|c|c|c|c|c|c|}
\hline $\begin{array}{l}\text { Please tick the relevant column for your answer } \\
\text { to each statement below }\end{array}$ & $\begin{array}{l}\text { Strongly } \\
\text { agree }\end{array}$ & Agree & Neutral & Disagree & $\begin{array}{l}\text { Strongly } \\
\text { disagree }\end{array}$ \\
\hline \multicolumn{6}{|l|}{ The exercise program has helped me manage my lung or heart condition more effectively } \\
\hline \multicolumn{6}{|l|}{ The exercise program was enjoyable } \\
\hline \multicolumn{6}{|l|}{ The exercise program has improved my fitness } \\
\hline \multicolumn{6}{|l|}{ The exercise program has improved my breathing when performing activities } \\
\hline \multicolumn{6}{|l|}{ The exercise program has improved my ability to exercise independently } \\
\hline \multicolumn{6}{|l|}{ I found the education booklet I received helpful } \\
\hline \multicolumn{6}{|l|}{ I would recommend this exercise program to others with a lung or heart condition } \\
\hline \multicolumn{6}{|l|}{ The venue of the exercise program was convenient for me (eg, transport/parking was easy) } \\
\hline \multicolumn{6}{|l|}{ I would like to continue the exercise program at this site } \\
\hline Overall, I am satisfied with the quality of service I received in delivering the exercise program & & & & & \\
\hline
\end{tabular}

\section{Publish your work in this journal}

The International Journal of COPD is an international, peer-reviewed journal of therapeutics and pharmacology focusing on concise rapid reporting of clinical studies and reviews in COPD. Special focus is given to the pathophysiological processes underlying the disease, intervention programs, patient focused education, and self management protocols.

\section{Dovepress}

This journal is indexed on PubMed Central, MedLine and CAS. The manuscript management system is completely online and includes a very quick and fair peer-review system, which is all easy to use. Visit $\mathrm{http}: / /$ www.dovepress.com/testimonials.php to read real quotes from published authors. 